Hinterlegte Botschaften 


\author{
Madeleine Marti
}

\title{
Hinterlegte Botschaften
}

\author{
Die Darstellung lesbischer Frauen \\ in der deutschsprachigen Literatur seit 1945
}




\section{METZLER STUDIENAUSGABE}

Die Zitate sind aus:

Adrienne Rich: Frauen und Ehre - Einige Gedanken

über das Lügen. In:

Dagmar Schultz (Hg.):

Macht und Sinnlichkeit, Orlanda Frauenverlag, Berlin 1983, S. 179

\section{Mary Daly: GYN/ÖKOLOGIE. Frauenoffensive Verlag,} München 1981, S. 15

Zugl.: Marburg, Univ. Diss., 1991

Die Deutsche Bibliothek - CIP-Einheitsaufnahme

Marti, Madeleine:

Hinterlegte Botschaften : die Darstellung lesbischer Frauen in der deutschsprachigen Literatur seit 1945 / Madeleine Marti. -

Stuttgart : Metzler, 1992

(Metzler-Studienausgaben)

Zugl,: Marburg, Univ., Diss., 1991

ISBN 978-3-476-00856-5

ISBN 978-3-476-00856-5 ISBN 978-3-476-03429-8 (eBook)

DOI $10.1007 / 978-3-476-03429-8$

Dieses Werk einschließlich aller seiner Teile ist urheberrechtlich geschützt. Jede Verwertung außerhalb der engen Grenzen des Urheberrechtsgesetzes ist ohne Zustimmung des Verlages unzulässig und strafbar. Das gilt insbesondere für Vervielfältigungen, Übersetzungen, Mikroverfilmungen und die Einspeicherung und Verarbeitung in elektronischen Systemen.

(C) 1992 Springer-Verlag GmbH Deutschland Ursprünglich erschienen bei J. B. Metzlersche Verlagsbuchhandlung und Carl Ernst Poeschel Verlag GmbH in Stuttgart 1992 
Die Liebe von Frauen zu anderen Frauen wurde fast gänzlich verschwiegen oder durch Lügen entstellt. Adrienne Rich

Es gehört ja zum Wesen der Frauenbewegung, dass wir ständig in Bewegung sind. Wir finden schliesslich die Botschaften, die wir an den in der Wildnis verstreuten Haltepunkten füreinander hinterlegt haben.

Mary Daly 


\section{Dank}

Allen, die mir bei meiner Arbeit geholfen haben, gilt mein herzlicher Dank.

Ganz besonders danke ich Prof. Dr. Marie Luise Gansberg für die engagierte Betreuung meiner Arbeit, also für Kritik und Ermutigung, wissenschaftliches Interesse und Diskussionsbereitschaft, freundschaftliche Unterstützung und Förderung.

Kontinuierliche Ermutigung und Diskussion, verbunden mit Beratung am Computer, erhielt ich von Dr. Doris Stump. Gespräche mit Prof. Dr. Ilse Kokula und Dr. Claudia Schoppmann gaben mir Informationen, Denkanstösse und stärkten mir den Rücken. Das Lektorat übernahm Regula Schnurrenberger.

Verschiedene Frauen haben einzelne Teile meiner Arbeit während der Entstehung kommentiert. Ausserdem danke ich allen Frauen, die mit mir in- oder ausserhalb von Arbeitsgruppen diskutierten, mir unpublizierte Arbeiten zur Verfügung stellten, mir Hinweise auf Texte gaben oder mich zu Vorträgen einluden.

In folgenden Bibliotheken fand ich bereits vergriffene Texte und unveröffentlichte Examensarbeiten: Denk(t)räume (Hamburg), Lesbenarchiv Spinnboden (Berlin/W.), Lesbenarchiv im Frauenzentrum (Bielefeld), FFBIZ (Berlin/W.), Frauenarchiv Schwarze Witwe (Münster).

Vom Schweizerischen Nationalfonds erhielt ich auf Antrag der Forschungskommission der SAGW ein Stipendium für 18 Monate. Der Fachbereich 9 der Universität Marburg nahm mich als Doktorandin an, nachdem ich das Studium in Zürich abgeschlossen hatte.

Beiträge an die Druckkosten leisteten meine Eltern und die Stiftung zur Erforschung der Frauenarbeit in Zürich. 


\section{Inhalt}

1. Einleitung

Erkenntnisinteresse und Vorgehen (7), Forschungssituation (11), Zur Verwendung der Begriffe lesbische Frau und Lesbe (20), Darstellung von Weiblichkeit und Ausgrenzung von Autorinnen (22), Paradox meiner Arbeit (28), Exkurs zu den fundamentalen Unterschieden zwischen Lesben und Schwulen (28)

2. Fünfziger Jahre

Gesellschaftliche Situation: Exkurs zur Entwicklung von 1900-1950 (36), Nach 1945 (42), Literarische Darstellungen (46)

2.1. Frauenfreundschaft in der Hetero-Realität Marlen Haushofer, Eine Handvoll Leben

Autorin (53), Interpretation von Eine Handvoll Leben (53), Zum zweiten Roman Die Tapetentür (76)

3. Sechziger Jahre

Gesellschaftliche Situation (82), Entwicklungen in der Literatur (85), Darstellungen lesbischer Frauen (86)

3.1. Grenzen durch das Tabu

Ingeborg Bachmann, Ein Schritt nach Gomorrha

Feministische Rezeption (92), Autorin (95), Interpretation von Ein Schritt nach Gomortha (96), Ähnlichkeiten bei Ingeborg Bachmann und Marlen Haushofer (107)

4. Ausgrenzung lesbischer Frauen im patriarchalen Literaturbetrieb und die Schaffung von Öffentlichkeit durch die Frauenbewegung (Exkurs)

Mănnerherrschaft auf dem Literaturmarkt (110), Interesse an Darstellungen homosexueller Mănner (114), Ausgrenzung von Darstellungen lesbischer Frauen (115), Die Frauenbewegung schafft Öffentlichkeit für Frauen (122), Ausgrenzung von Frauenverlagen und ihren Autorinnen (132)

5. Siebziger Jahre

Gesellschaftliche Situation (135), Literarische Darstellungen (139), Zur Auswahl der Texte (143) 
5.1. Lesbische Traditionsbildung

Johanna Moosdorf, Die Freundinnen

Autorin (147), Uberblick uber die frühen Texte (148), Interpretation von Die

Freundinnen (153) Ausblick auf Jahrhunderttrume (176)

\subsection{Von der schwulen Maskierung zur Dokumentation}

Marlene Stenten, Der Zwerg und die Königin

Autorin (179), Uberblick uber Stentens Texte (180), Exemplarische Interpretation von Der Zwerg und die Königin (188)

6. Achtziger Jahre

Gesellschaftliche Situation (198), Literaturbetrieb (203), Literarische Darstellungen (205), Zur Auswahl der Texte (206), Zu einzelnen Texten (206)

6.1. Verständigungstext für Lesben Judith Offenbach, Sonja

Autobiographische Berichte von Lesben (210), Feministische Rezeption (214), Zur Autorin und zu weiteren Texten von Offenbach (216), Interpretation von Sonja (217)

\subsection{Lesbische Frauen in der DDR-Literatur}

Waldtraut Lewin, Dich hat Amor gewiss ...

Zur gesellschaftlichen Situation (244), Andeutungen in literarischen Texten (251), Waldtraut Lewin, Dich hat Amor gewiss ... (260), Autorin (261), Fruhere Texte (261), Interpretation (264), Rezeption in der DDR (275)

\subsection{Lesbische Frauen in der Schweizer Literatur} Gertrud Wilker, Nachleben

Zur politischen Organisierung (279), Zu Gertrud Isolani, Stadt ohne Männer (282), Schweizer Schriftstellerinnen in den siebziger Jahren (284), Gertrud Wilker, Autorin (288), Fruhere Texte (289), Interpretation von Nachleben (289), Ausblick auf spätere Texte (305)

7. Vom männlichen zum lesbischen Ich

Christa Reinigs Literatur von den fünfziger bis in die achtziger Jahre

Autorin (311), Literarisches Werk: 1945-1974 (316), Lyrik (323), Erzałhlungen (329), Die Romane: Die himmlische und die irdische Geometrie (331), Entmannung (341), Prosa von 1979 bis 1983 (356), Die Frou im Brunnen (358) 
8. Traditionsbildung und Veränderung

Lesbische Traditionsbildung (368), $\mathrm{Zu}$ den einzelnen Autorinnen (370), Tendenzen der Verănderung (381), Perspektiven (389)

9. Verzeichnis deutschprachiger Literatur mit Darstellungen lesbischer Frauen von 1945 bis 1990

10. Bibliographie

10.1. Primărliteratur

S.405

Interpretierte Texte (405), Weitere zitierte Texte (411)

10.2. Sekundärliteratur 